\title{
PERENCANAAN SARANA PENGOLAHAN AIR LIMBAH DOMESTIK BERBASIS MASYARAKAT DI DAERAH PESISIR (STUDI KASUS : DESA PURWOREJO, KECAMATAN BONANG, KABUPATEN DEMAK)
}

\author{
Sri Wahyuni, Lili Mulyatna*, Linda Qomariyah
}

Program Studi Teknik Lingkungan, Universitas Pasundan

\begin{abstract}
Abstrak
Desa Purworejo sebagai desa nelayan yang memiliki sarana pengolahan air limbah domestik minim. Permasalahan ini diperparah dengan kebiasaan sebagian besar penduduknya melakukan kegiatan buang air besar sembarangan. Hal ini, menunjukkan rendahnya pola hidup sehat dan bersih pada masyarakat.Perencanaan ini berguna untuk meningkatkan akses dan memenuhi kebutuhan masyarakat terhadap sarana pengolahan air limbah domestik di wilayah pesisir. Data primer yang dikumpulkan dengan survey dan penyebaran kuisioner digunakan untuk bahan pertimbangan pemilihan teknologi yang akan diterapkan.Teknologi yang dipilih untuk pengolahan air limbah adalah Tripikon-S diterapkan pada masyarakat yang rumahnya berdekatan dengan bibir pantai sebanyak 224 unit, tangki septik komunal untuk daerah yang berjauhan dari bibir pantai dan sebagian besar memiliki jamban sendiri sebanyak 147 unit, sedangkan untuk Mandi Cuci Kakus (MCK) ++ (ruang mandi 4 unit, ruang cuci 2 unit, ruang kakus 4 unit) dengan 2 unit Anaerobic Baffled Reactor untuk daerah yang tidak memiliki prasarana MCK, jarak tempat tinggal masyarakat yang berdekatan, dan luas lahan rumah yang relatif sangat kecil.
\end{abstract}

Kata kunci: Anaerobic Baffled Reactor, daerah pesisir, sanitasi masyarakat, tangki septik komunal, Tripikon-S

\section{Pendahuluan}

Desa Purworejo merupakan salah satu desa di Kecamatan Bonang, Kabupaten Demak.Secara umum, Desa Purworejo adalah daerah pesisir pantai dan menjadi pusat pelabuhan ikan serta permukiman masyarakat nelayan di Kabupaten Demak.

Sebagian besar masyarakat Desa Purworejo mata pencaharian utama sebagai nelayan yang menjual ikan di Tempat Pelelangan Ikan (TPI) yang secara langsung dapat meningkatkan pendapatan bagi masyarakat lokal dan

\footnotetext{
${ }^{*}$ Penulis Korespondensi:

E-mail: lili.mulyatna@gmail.com

Diterima pertama kali: 8 Maret 2017

Direvisi : 23 Juni 2017

Disetujui untuk publikasi: 30 Juli 2017
}

pemerintah setempat.Hal ini, berbanding lurus dengan pertumbuhan penduduk dan aktivitas pembangunan yang semakin tinggi. Namun, pada sisi lain teridentifikasi adanya penurunan kualitas lingkungan karena pengaruh eksploitasi sumber daya alam terutama air serta pengaruh dari limbah cair dan padat dari aktivitas kehidupan setempat akibat dari ketidakseimbangan peningkatan kualitas dan kuantitas fasilitas sanitasi lingkungan pesisir setempat, serta kurangnya tingkat kesadaran, kepedulian, dan pengetahuan masyarakat akan sanitasi dan kesehatan lingkungan.

Penurunan kualitas lingkungan tersebut dapat terlihat dari masih banyak ditemukannya masyarakat yang tidak memiliki jamban di rumah.Sehingga masyarakat membuang tinja di 
sungai sekitar, serta adanya saluran pembuangan air limbah yang langsung dialirkan ke laut. Hal ini, menjadi suatu masalah yang perlu mendapatkan perhatian karena akan berpengaruh pada kesehatan masyarakat secara khusus dan menimbulkan pencemaran laut dan pesisir.

Berdasarkan kondisi tersebut di atas, maka dalam kajian ini akan direncanakan pengembangan sarana dan prasarana sanitasi dengan berbasis masyarakat bagi masyarakat yang bermukim di wilayah pesisir pantai.

\section{Metodologi Kajian}

\section{Data Primer}

Data primer diperoleh dari pengumpulan data yang berasal dari sumber data pertama yang diambil langsung dari lapangan. Sumber data primer dapat berupa responden atau subyek yang dijadikan riset dari hasil pengisian wawancara, kuisioner dan observasi (Kriyantono, 2009).

Pengumpulan data yang dilakukan dalam Tugas Akhir ini adalah dengan survey lapangan dan kuisioner. Metode survey merupakan metode penelitian untuk memperoleh data yang sesuai dengan fakta-fakta di lapangan. Metode Survey yang digunakan adalah inspeksi sanitasi yang bertujuan untuk menganalisis risiko yang diakibatkan sarana dan prasarana sanitasi di daerah studi. Selain itu juga menggunakanmetode Real Demand Survey (RDS) yang bertujuan untuk mengetahui kondisi sarana dan prasarana eksisting mengenai sanitasi, higienitas, serta perilaku masyarakat dalam masalah kesehatan lingkungan, mengetahui tingkat kebutuhan masyarakat terhadap sarana dan prasarana air bersih, air limbah, persampahan, dan drainase serta untuk menentukan prioritas dalam menyediaan dan pembangunan sarana dan prasarana sanitasi (Anonim, 2008).

Penyebaran kuisioner dilakukan setelah melakukan perhitungan jumlah sampel yang diperlukan dalam suatu populasi. Hal ini dilakukan untuk menghemat biaya, waktu, dan tenaga. Untuk menghitung hasil kuisioner dengan menggunakan rumus sebagai berikut :

- Nilai Survey $=\frac{\text { Jumla } h \text { Jawaban }}{\text { Jumla } h \text { sampel }} \times 100 \%$

- Total Nilai Risiko $=\frac{\text { Jumlah Jawaban "Ya" }}{\text { Jumlah soal }} \times$ Jumlah soal

Nilai Risiko:9-10 = Sangat Tinggi; $7-8=$ Tinggi; $4-6=$ Menengah $; 0-3=$ Rendah

\section{Pengambilan Sampel}

Untuk menentukan jumlah sampel yang akan diambil dengan menggunakan rumus Slovin. Hal ini didasari atas jumlah populasinya sudah diketahui sebelumnya (Ariola \& Ellen, 2006).

Persamaan rumus yang digunakan adalah :

$\mathbf{n}=\frac{\mathbf{N}}{1+\mathrm{Ne}^{2}}$

Dimana :

$\mathrm{n}=$ Jumlah sampel (Kepala Keluarga/KK)

$\mathrm{N}=$ Jumlah populasi $(\mathrm{KK})$

$\mathrm{e}=$ Derajat kecermatan atau toleransi kesalahan dalam pengambilan sampel $10 \%$

Sehingga :

$n=\frac{N}{1+N e^{2}}=\frac{2.603}{1+2.603 \times 0,1^{2}}=96,3 \mathrm{KK}=97 \mathrm{KK}$

Berdasarkan perhitungan rumus Slovin di atas, maka dapat diketahui jumlah sampel responden yang ditentukan untuk pengisian kuisioner adalah sebanyak 97 (KK) sampel.

Pemilihan responden dilakukan secara acak berdasarkan pada jumlah sampel KK pada tiap RW.Berikut rumus yang digunakan dalam penentuan pengambilan sampel :

$f i=\frac{N i}{N}$

ni $=\mathbf{f i} \times \mathbf{x}$

Keterangan :

fi=Sampling fraction cluster

$\mathrm{Ni}=$ Banyaknya individu yang ada dalam cluster 
$\mathrm{N}=$ Banyaknya anggota yang dimasukkan sampel ni=Banyaknya anggota yang dimasukkan menjadi sub sampel

Maka, contoh perhitungan untuk masing-masing RW di Desa Purworejo ini adalah sebagai berikut :

$f i=\frac{401}{2.603}=0,15$

$\mathrm{ni}=0,15 \times 97=14,55 \approx 15 \mathrm{KK}$

Berikut tabel Sistem Sampel yang diambil secara acak kelompok :

Tabel 1. Sistem Sampel Secara Acak

\begin{tabular}{ccc}
\hline RW & Jumlah Populasi & $\begin{array}{c}\text { Jumlah } \\
\text { Sampel }\end{array}$ \\
\hline 01 & $401 \mathrm{KK}$ & 15 \\
\hline 02 & $397 \mathrm{KK}$ & 15 \\
\hline 03 & $462 \mathrm{KK}$ & 17 \\
\hline 04 & $403 \mathrm{KK}$ & 15 \\
\hline 05 & $374 \mathrm{KK}$ & 14 \\
\hline 06 & $269 \mathrm{KK}$ & 10 \\
\hline 07 & $297 \mathrm{KK}$ & 11 \\
\hline Jumlah & $\mathbf{2 . 6 0 3 ~ K K}$ & $\mathbf{9 7}$ \\
\hline
\end{tabular}

\section{Hasil dan Pembahasan}

Masalah sanitasi yang terjadi di daerah studi diketahui dari hasil pengamatan dan survey serta penyebaran kuisioner terhadap masyarakat Desa Purworejo. Cara pengisian kuisioner dilakukan dengan cara wawancara langsung dengan masyarakat. Kuisioner disebar sebanyak 97 sampel KK yang diperoleh dari hasil perhitungan Slovin.

\section{Hasil KuisionerAkses Air Limbah}

Untuk akses air limbah di daerah studi terdiri dari beberapa komponen yang tersaji dalam kuisioner. Beberapa aspek yang menjadi perhatian dalam kuisioner tersebut antara lain tempat anggota keluarga melakukan kegiatan buang air besar (BAB), pengetahuan bahaya buang air besar sembarangan (BABS), tempat disalurkannya air limbah, dan tempat disalurkannya air bekas cuci.

Aspek pertama yaitu mengenai tempat anggota keluarga melakukan BAB dari 97 responden terdapat 61 responden melakukannya di sungai/pantai, jamban sendiri 32 responden, 3 responden MCK umum, dan 1 responden menggunakan jamban bersama karena jumlah kepala keluarga yang menggunakan lebih dari 3 Kepala Keluarga yakni 5 Kepala Keluarga.

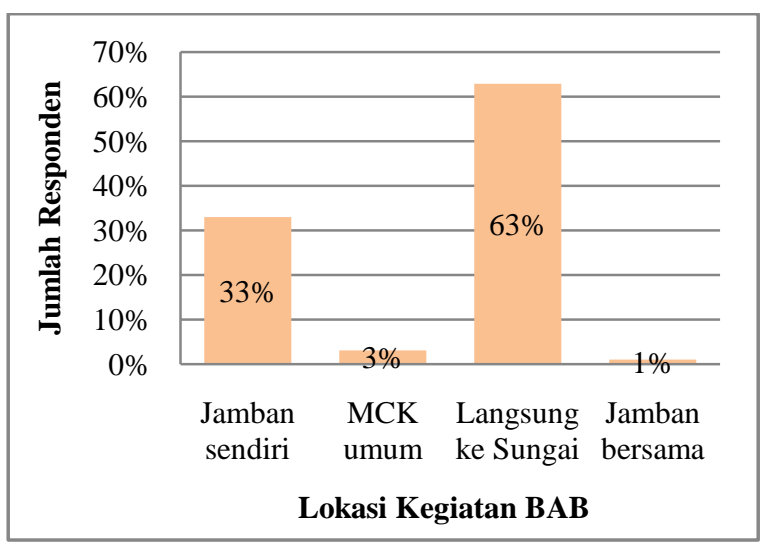

Gambar 1. Tempat Kegiatan BAB Responden

Alasan responden banyak yang melakukan kegiatan $\mathrm{BAB}$ di ruang terbuka yaitu sungai/pantai di karenakan selain dekat dengan sungai dan pantai dengan alasan praktis tingkat kesadaran tentang bahaya BABS masih rendah. Hal ini dapat ditunjukkan dengan hasil survey yang diperoleh dari 97 responden terdapat 58 responden tahu bahaya BABS, 22 responden tidak mengetahui, dan 17 responden tidak dapat menjawab.

Dari 32 responden yang menggunakan jamban sendiri, 3 responden MCK umum, dan 1 responden menggunakan jamban bersama air limbah dari kegiatan domestik (kagiatan $\mathrm{BAB} /$ tinja dan urin) disalurkan ke cubluk sebanyak 16 responden dan 20 responden menyalurkannya ke sungai/laut. 
Responden yang menyalurkan air limbah domestik (tinja dan urin) ke dalam cubluk yang tidak kedap air dan ditutup secara permanen.Karena kondisi tanah di daerah studi yang berupa pasir serta konstruksi dari cubluk yang tidak kedap air, maka air limbah tidak mengalami luapan (terisi penuh) meskipun telah digunakan cukup lama. Hal ini dimungkinkan karena daya resap tanah yang tinggi sehingga responden tidak pernah melakukan pembersihan atau pengangkatan, menimbun lubang, dan mengganti lubang dengan yang baru. Cubluk di letakkan di bawah dapur dan di tutup dengan lantai rumah/keramik.

Untuk air bekas cuci responden tidak ada yang menggunakan instalasi penampungan khusus air bekas cuci ataupun di salurkan ke cubluk.Dari 97 responden semua menyalurkan air bekas cuci ke selokan kemudian mengalir langsung ke sungai dan laut.

Adapula responden yang langsung membuang air bekas cuci ke sungai langsung karena belakang rumah tinggalnya di pinggir sungai.

\section{Kebutuhan Sarana Air Limbah}

Kebutuhan sarana dan prasarana sanitasi diperlukan untuk mengetahui tanggapan masyarakat terhadap sarana dan prasarana sanitasi yang dibutuhkan.Hasil kuisioner kepada 97 responden di daerah studi diketahui bahwa 39 responden membutuhkan sarana dan prasarana air limbah.

\section{Hasil Inspeksi Air Limbah}

Inspeksi sanitasi yang dilakukan di daerah studi dengan cara melakukan pengamatan langsung dan mewawancarai responden dengan kuisioner untuk melihat kondisi sanitasi. Tujuan dari inspeksi sanitasi ini adalah untuk masukan rencana pengembangan sanitasi berdasarkan nilai risiko.
Tabel 2. Tempat Kegiatan Buang Air Besar (BAB)

\begin{tabular}{ccccc}
\hline RW & $\begin{array}{c}\text { Jamban } \\
\text { sendiri }\end{array}$ & $\begin{array}{c}\text { MCK } \\
\text { Umum }\end{array}$ & BABS & $\begin{array}{c}\text { Jamban } \\
\text { Bersama }\end{array}$ \\
\hline 01 & 3 & 0 & 11 & 1 \\
\hline 02 & 4 & 0 & 11 & 0 \\
\hline 03 & 5 & 0 & 12 & 0 \\
\hline 04 & 11 & 3 & 1 & 0 \\
\hline 05 & 3 & 0 & 11 & 0 \\
\hline 06 & 2 & 0 & 8 & 0 \\
\hline 07 & 4 & 0 & 7 & 0 \\
\hline Total & $\mathbf{3 2}$ & $\mathbf{3}$ & $\mathbf{6 1}$ & $\mathbf{1}$ \\
\hline
\end{tabular}

Tabel 3. Penilaian Risiko Kepemilikan Jamban Untuk Setiap RW

\begin{tabular}{cccccc}
\hline RW & $\begin{array}{c}\text { Sam- } \\
\text { pel }\end{array}$ & $\begin{array}{c}\text { Sangat } \\
\text { Tinggi } \\
(\mathbf{8 - 9})\end{array}$ & $\begin{array}{c}\text { Tinggi } \\
(\mathbf{6 - 7})\end{array}$ & $\begin{array}{c}\text { Mene- } \\
\text { ngah } \\
(\mathbf{3 - 5})\end{array}$ & $\begin{array}{c}\text { Rendah } \\
(\mathbf{0 - 2})\end{array}$ \\
\hline 01 & 15 & 0 & 0 & 0 & 4 \\
\hline 02 & 15 & 0 & 0 & 2 & 2 \\
\hline 03 & 17 & 0 & 0 & 2 & 3 \\
\hline 04 & 15 & 0 & 0 & 0 & 14 \\
\hline 05 & 14 & 0 & 0 & 0 & 3 \\
\hline 06 & 10 & 0 & 0 & 0 & 2 \\
\hline 07 & 11 & 0 & 0 & 0 & 4 \\
\hline Total & $\mathbf{9 7}$ & & & & \\
\hline
\end{tabular}

Secara keseluruhan dari hasil nilai risiko responden yang menggunakan jamban sendiri, jamban bersama, dan MCK Umum mendapat skor 0-2 (Rendah) sebanyak 32 responden dan skor 3-5 (Menengah) sebanyak 4 responden.Disimpulkan bahwa risiko kepemilikan jamban cenderung "Rendah".

Namun dari 36 responden yang memiliki jamban terdapat 20 responden yang menyalurkan air limbah domestik (black water) ke saluran sungai/laut.Sedangkan 61 responden melakukan BABS di saluran terbuka seperti sungai/laut.Hal ini dapat membahayakan masyarakat baik secara kesehatan maupun keselamatan sehingga dibutuhkan sarana dan prasarana air limbah.

\section{Pemilihan Opsi Teknologi Untuk Air Limbah}

Pemilihan opsi teknologi untuk air limbah dipengaruhi oleh aspek teknis dan non teknis. Untuk hasil penjumlahan dari pembobotan 
masing-masing teknologi yang akan dipilih adalah alternatif teknologi yang memiliki jumlah pembobotan paling tinggi. Skor yang ditentukan memiliki rentang 1-3 dengan ketentuan 1 adalah untuk nilai tinggi/sulit, nilai 2 adalah sedang, dan nilai 3 adalah rendah/mudah.

Berdasarkan hasil analisa alternatif teknologi yang terpilih adalah teknologi Anaerobic Baffled
Reactor (ABR). Tripikon-S dipilih untuk masyarakat yang rumahnya berdekatan dengan bibir pantai untuk meminimalkan dampak pasang surut air laut terhadap teknologi yang diterapkan.Sedangkan untuk tangki septik komunal diaplikasikan untuk rumah warga yang jaraknya jauh dari bibir pantai karena tidak terpengaruh dampak pasang surut secara langsung.

Tabel 4. Matriks Pemilihan Opsi Teknologi Air Limbah Domestik

\begin{tabular}{|c|c|c|c|c|c|c|c|}
\hline \multirow[b]{2}{*}{ Teknologi } & \multicolumn{4}{|c|}{ Aspek Teknis } & \multicolumn{2}{|c|}{ Non Teknis } & \multirow[b]{2}{*}{$\sum$} \\
\hline & $\begin{array}{l}\text { Penyisihan } \\
\text { Parameter } \\
\text { Pencemar }\end{array}$ & Operasional & Biaya & Lahan & Sosial & $\begin{array}{l}\text { Tingkat } \\
\text { Ekonomi }\end{array}$ & \\
\hline $\begin{array}{c}\text { Anaerobic } \\
\text { Upflow Filter } \\
\text { (AUF) }\end{array}$ & 2 & 2 & 3 & 2 & 3 & 2 & 14 \\
\hline $\begin{array}{c}\text { Anaerobic } \\
\text { Baffled Reactor } \\
\text { (ABR) }\end{array}$ & 3 & 3 & 3 & 3 & 3 & 2 & 17 \\
\hline $\begin{array}{c}\text { Biofiltrasi } \\
\text { dengan tangki } \\
\text { fiber }\end{array}$ & 3 & 3 & 3 & 1 & 3 & 2 & 15 \\
\hline Tripikon-S & 1 & 1 & 3 & 3 & 3 & 2 & 13 \\
\hline T-Pikon-H & 1 & 1 & 3 & 3 & 3 & 2 & 13 \\
\hline $\begin{array}{c}\text { Tangki septik } \\
\text { komunal }\end{array}$ & 1 & 3 & 3 & 1 & 3 & 2 & 13 \\
\hline
\end{tabular}

\section{Perencanaan Sarana Air Limbah Domestik}

Jumlah keseluruhan penduduk Desa Purworejo 10 tahun terakhir dapat dilihat pada Tabel 5.

Tabel 5. Jumlah Penduduk Desa Purworejo 10 Tahun Terakhir

\begin{tabular}{cc}
\hline Tahun & $\begin{array}{c}\text { Jumlah Penduduk } \\
\text { (Jiwa) }\end{array}$ \\
\hline 2004 & 8.695 \\
\hline 2005 & 8.795 \\
\hline 2006 & 8.898 \\
\hline 2007 & 9.002 \\
\hline 2008 & 9.107 \\
\hline 2009 & 9.227 \\
\hline 2010 & 9.352 \\
\hline
\end{tabular}

\begin{tabular}{ll}
\hline 2011 & 9.462 \\
\hline 2012 & 9.577 \\
\hline 2013 & 9.697 \\
\hline
\end{tabular}

Pemilihan metode proyeksi yang akan disesuikan dengan kriteria dapat dilakukan secara statistik yaitu dengan menggunakan rumus standar deviasi (SD) dan rumus koefisien kolerasi (r). Penggunaan koefisien kolerasi dimaksudkan untuk menunjukkan tingginya derajat hubungan antara dua variabel (x dan y), maka dari itu nilai koefisien kolerasi harus mendekati 1, sedangkan standar deviasi digunakan untuk menghomogenkan data, maka dari itu nilai standar deviasi dipilih nilai yang paling kecil. 
Metode proyeksi jumlah penduduk menggunakan 3 metode sebagai bahan perbandingannya. Ketiga metode tersebut antara lain adalah :

- Metode Aritmatika

- Metode Geometri

- Metode Least square

Berikut ini adalah hasil perhitungan nilai koefisien korelasi dan standar deviasi dari tiga metode yang digunakan :

Tabel 6. Kategori Penilaian Koefisien Korelasi

\begin{tabular}{lcc}
\hline \multicolumn{1}{c}{ Metode } & $\begin{array}{c}\text { Koefisien } \\
\text { Korelasi (r) }\end{array}$ & $\begin{array}{c}\text { Standar } \\
\text { Deviasi (SD) }\end{array}$ \\
\hline Aritmatika & 0,9995 & 20,347 \\
\hline Geometri & $\mathbf{0 , 9 9 9 8}$ & $\mathbf{1 0 , 6 3 0}$ \\
\hline Least Square & 0,9995 & 11,640 \\
\hline $\begin{array}{l}\text { Dengan adanya } \\
\text { atas, maka metode proyeksi yang terpilih adalah }\end{array}$ \\
$\begin{array}{l}\text { Geometri karena koefisien } \\
\text { besar dan mendekatinya paling }\end{array}$ \\
penduduk dengan menggunakan Geometri dapat \\
dilihat pada Tabel 7.
\end{tabular}

Tabel 7. Proyeksi Penduduk 15 Tahun

Mendatang

\begin{tabular}{cc}
\hline Tahun & Jumlah Penduduk (Jiwa) \\
\hline 2018 & 10.303 \\
\hline 2019 & 10.428 \\
\hline 2020 & 10.556 \\
\hline 2021 & 10.684 \\
\hline 2022 & 10.814 \\
\hline 2023 & 10.946 \\
\hline 2024 & 11.080 \\
\hline 2025 & 11.215 \\
\hline 2026 & 11.352 \\
\hline 2027 & 11.490 \\
\hline 2028 & 11.630 \\
\hline 2029 & 11.772 \\
\hline 2030 & 11.915 \\
\hline 2031 & 12.061 \\
\hline 2032 & 12.208 \\
\hline 2033 & 12.357
\end{tabular}

Perhitungan desain teknis teknologi air limbah di daerah studi harus diperhatikan mengingat merupakan daerah spesifik. Untuk itu, akan direncanakan teknologi pengolahan air limbah dengan 3 teknologi, yaitu :

- ABR (Anaerobic Baffled Reactor) merupakan teknologi yang terpilih berdasarkan matriks pemilihan opsi teknologi.

- Tripikon-S dipilih karena untuk masyarakat yang rumahnya berdekatan dengan bibir pantai guna meminimalkan dampak pasang surut air laut terhadap teknologi yang diterapkan.

- Tangki septik komunaldiaplikasikan untuk rumah warga yang jaraknya jauh dari bibir pantai karena tidak terpengaruh dampak pasang surut secara langsung.

\section{$\underline{\text { Tripikon-S }}$}

Penentuan dimensi Tripikon-S berdasarkan pada tabel pembebanan Tripikon-S dan kapasitas jumlah orang tipikal yang dikeluarkan oleh Laboratorium Teknik Sipil Tradisional Fakultas Teknik UGM, Yogyakarta tahun 2002.Tripikon$S$ yang direncanakan bersifat komunal dengan kapasitas $2-3 \mathrm{KK}$ atau sekitar 8-11 orang. Adapun dimensinya dapat dilihat pada tabel dibawah ini :

Tabel 8. Dimensi Tripikon-S yang

Direncanakan Kapasitas 3 KK

\begin{tabular}{cc}
\hline Dimensi & Satuan \\
\hline Panjang & $10 \mathrm{~m}$ \\
\hline Diameter & $30 \mathrm{~cm}$ \\
\hline Beban & $235 \mathrm{l} / \mathrm{hari}$ \\
\hline
\end{tabular}

Dari tabel diatas, maka dapat dihitung kebutuhan Tripikon-S di daerah studi adalah jumlah KK dengan jarak rumah yang berdekatan dengan bibir pantai sebanyak 671 KK.Kapasitas Tripikon yang direncanakan berkapasitas $3 \mathrm{KK}$ (11 orang).Maka jumlah Tripikon-S yang dibutuhkan sebanyak 224 buah

Berikut adalah gambar sketsa dari Tripikon-S: 


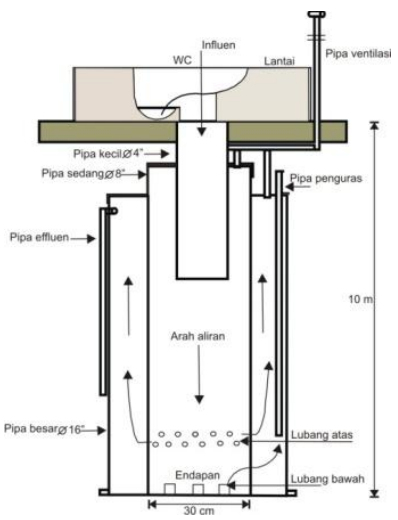

Gambar 4. Sketsa Tripikon-S

\section{* Desain Tipikal MCK + +}

MCK Plus ++ yang direncanakan dapat melayani kapasitas 2.994 orang sehingga diperlukan perhitungan jumlah ruang MCK menggunakan rumus yang telah tercantum pada SNI 03-2399-2002 tentang Tata Cara Perencanaan Bangunan MCK. Umum. Banyaknya ruang mandi, cuci dan kakus yang dibutuhkan adalah :

- $\operatorname{Kamar}$ Mandi $(\mathrm{M})=4$ ruang/2 ABR

- Ruang Cuci $(\mathrm{C}) \quad=2$ ruang/ 2 ABR

- Ruang Kakus (K) = 4 ruang/ 2 ABR

\section{ABR (Anaerobic Baffled Reactor)}

Direncanakan di daerah studi akan menggunakan $2 \mathrm{ABR}$.

Tabel 8. Perhitungan Dimensi ABR

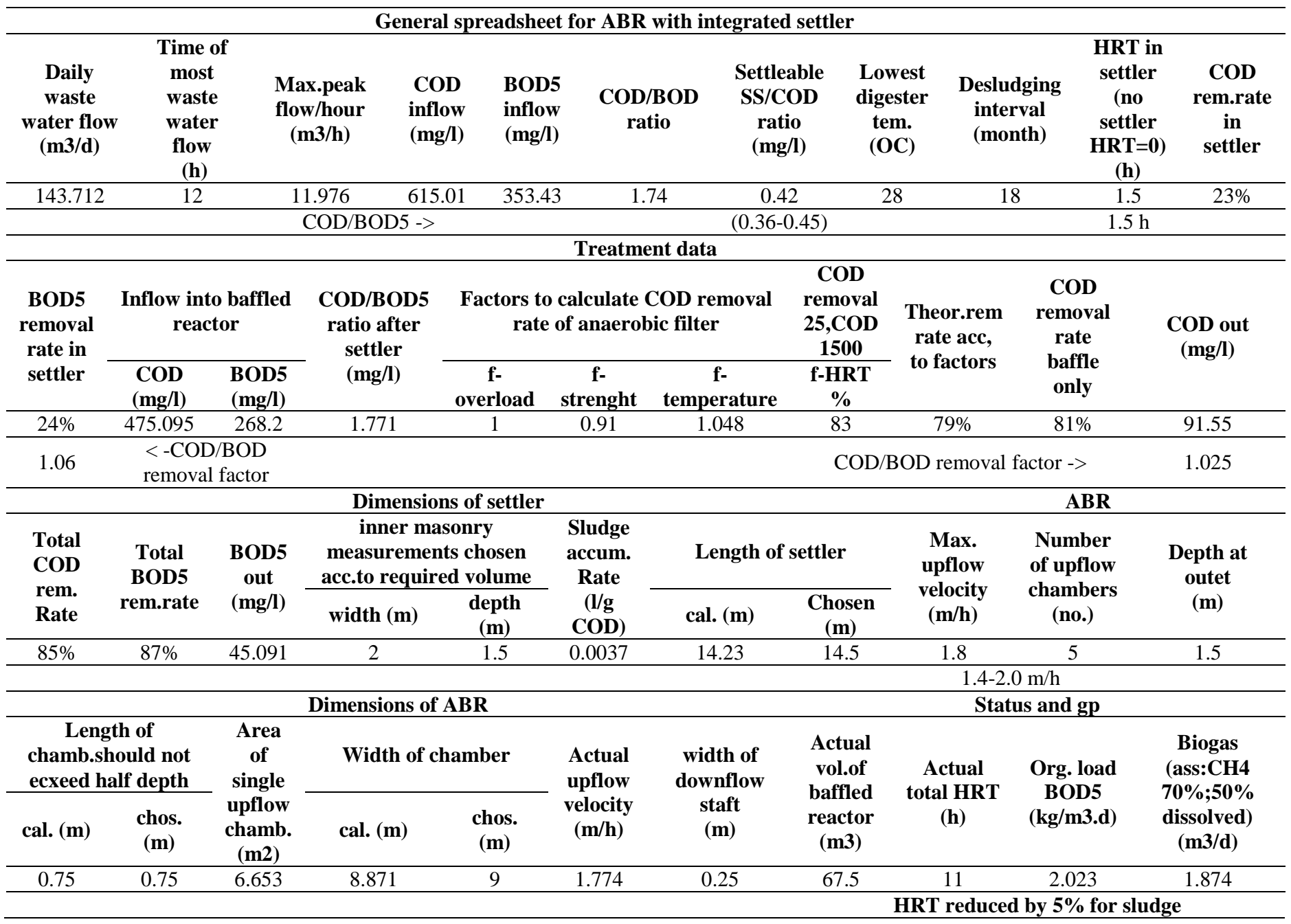




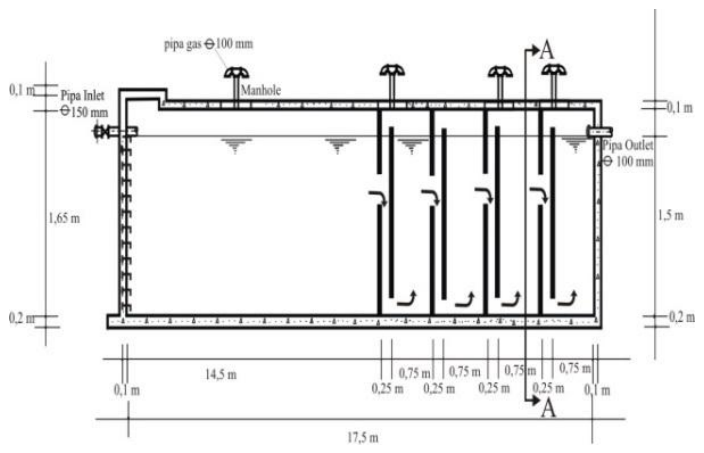

Gambar 5. Sketsa Potongan Membujur ABR

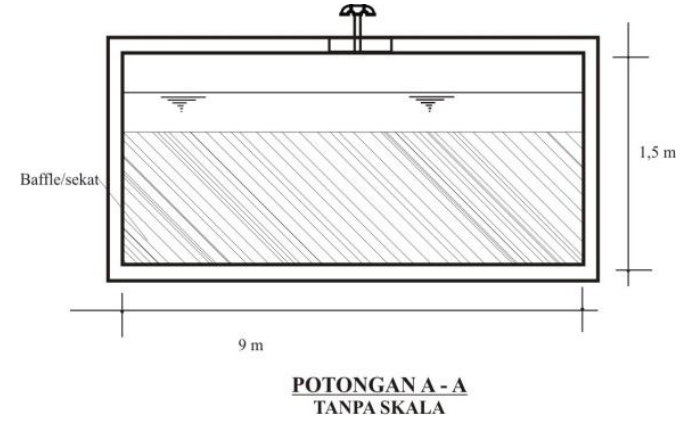

Gambar 9. Sketsa Potongan Melintang ABR

\section{Tangki Septik Komunal}

Tangki septik komunal diaplikasikan bagi rumah warga yang jauh dari bibir pantai karena tidak langsung terpengaruh dampak pasang surut.

Dimensi dari tangki septik komunal dengan kapasitas $10 \mathrm{KK}$ (50 jiwa) adalah $\mathrm{P} \times \mathrm{L} \times \mathrm{T}=$ $2,8 \times 1,4 \times 1,8 \mathrm{~m}$. Volume lumpur yang dihasilkan sebanyak $6 \mathrm{~m}^{3}$ dan volume air $0,845 \mathrm{~m}^{3}$ dengan waktu pengurasan 3 tahun.

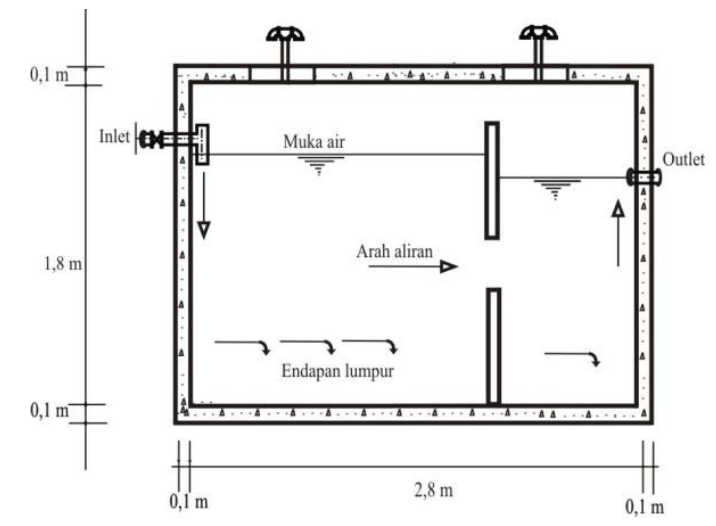

Gambar 10. Sketsa Tangki Septik
Jumlah KK yang harus dilayani adalah $1470 \mathrm{KK}$ (7350 jiwa). Kapasitas tangka septik yang direncanakan untuk 10 KK (50 jiwa). Sehingga, diperlukan 147 unit tangki septik komunal untuk melayani warga di daerah studi.

\section{Kesimpulan}

Berdasarkan dari uraian dan penjelasan dari hasil penelitian di daerah studi Desa Purworejo mengenai sarana pengolahan air limbah domestik dapat disimpulkan sebagai berikut :

- Hasil survey yang dilakukan di Desa Purworejo menunjukkan bahwa tingkat kelayakan sarana dan prasarana sanitasi masih sangat minim. Hal ini ditunjukkan dengan masih banyak ditemukan masyarakat yang melakukan BABS.

- Teknologi yang terpilih adalah teknologi Anaerobic Baffled Reactor (ABR) sebanyak 2 unit yang dilengkapi dengan $\mathrm{MCK}++$ (ruang mandi 4 unit, ruang cuci 2 unit, ruang kakus 4 unit). Tripikon-S dipilih untuk masyarakat yang rumahnya berdekatan dengan bibir pantai untuk meminimalkan dampak pasang surut air laut terhadap teknologi yang diterapkan sebanyak 224 unit. Sedangkan untuk tangki septik komunal diaplikasikan untuk rumah warga yang jaraknya jauh dari bibir pantai karena tidak terpengaruh dampak pasang surut secara langsung sebanyak 147 unit.

\section{Daftar Pustaka}

Anonim. (2008). Higiene dan Sanitasi Pengolahan Pangan. Retrieved Juni 21, 2014, dari Higiene dan Sanitasi Pengolahan Pangan: http://mankester.wordpress.com/

Ariola, \& Ellen, S. (2006). Principles and Methods of Research. Rex Bookstore, Inc.

Kriyantono, R. (2009). Teknik Praktis Riset Komunikasi. Malang: Prenada Media Group. 